\title{
Effect of traditional resistance training on blood pressure in normotensive elderly persons: a systematic review of randomized controlled trials and meta-analyses
}

Durcelina Schiavonil-3 Ligia Maxwell Pereira² Hugo Maxwell Pereira² Edilson Serpeloni Cyrino ${ }^{3}$ Jefferson Rosa Cardoso²

\section{Abstract}

The objective of the present study was to determine the effectiveness of the regular practice of traditional resistance training (RT) on systolic (SBP) and diastolic blood pressure (DBP) in normotensive elderly persons. A systematic review of randomized clinical trials and meta-analyses was performed. Searches were performed without language restrictions in different databases. Randomized clinical trials published from 1966 to 2010 that assessed the effects of traditional RT on resting blood pressure (BP) and/or for the treatment of high BP were included. Only studies that assessed the effects of traditional RT on elderly adults, regardless of the number of exercises, with the presence of a control group and comparisons between groups, were included. Twenty-nine studies were found, but only six met the inclusion criteria. The mean difference was used for meta-analysis, using a 95\% confidence interval and a random effect model. Traditional RT induced a significant decrease in SBP $(-6.63 \mathrm{mmHg} ; p=0.02)$ but not in DBP $(-3.34$ $\mathrm{mmHg} ;=0.11)$. These results suggest that traditional RT may be a non-pharmacological strategy for the control of BP in the elderly.

\footnotetext{
Universidade Paranaense, Departamento de Ciências Biológicas Médicas e da Saúde, Francisco Beltrão. Cidade, PR, Brasil.

2 Universidade Estadual de Londrina, Laboratório de Biomecânica e Epidemiologia Clínica, Grupo de Pesquisa e Intervenção em Fisioterapia (PAIFIT). Londrina, PR, Brasil.

3 Grupo de Estudo e Pesquisa em Metabolismo, Nutrição e Exercício (GEPEMENE). Universidade Estadual de Londrina, Centro de Educação Física e Esporte. Londrina, PR, Brasil.
}

Keywords: Resistance Training. Blood Pressure. Elderly. 


\section{INTRODUCTION}

Arterial hypertension (AH) is an important cardiovascular risk factor as it is the most common condition observed in primary care and can lead to myocardial infarction, strokes, renal failure and, consequently, death, if not detected early and treated properly $^{1,2}$.

Age is one of the main non-controllable risk factors associated with the chronic elevation of blood pressure (BP), as aging leads to structural and functional alterations in the cardiovascular system, such as stiffening of the arteries and the decline of BP control mechanisms, among others, contributing to the increased prevalence of $\mathrm{AH}$, especially from the fifth decade of life onwards ${ }^{4}$.

The regular practice of physical exercise among the elderly has been recommended as a way of mitigating or reversing numerous deleterious effects on morphological, neuromuscular, metabolic, physiological and psychological variables associated with aging ${ }^{5}$. Thus, physical exercise can play an important role in the prevention or treatment of hypertension, and is a non-pharmacological strategy that can also contribute to the improvement of functional capacity and consequently the quality of life of the elderly.

Although the efficacy of physical exercises with predominantly aerobic characteristics in improving BP has been proven ${ }^{6-8}$, this type of physical exercise is somewhat limited in relation to gains in strength and muscle power, muscle mass and bone mineral density, which are fundamental adaptations for static and dynamic stability, balance, coordination and gait, especially in the elderly. Resistance exercises and, in particular, resistance training (RT), however, are recognized as the most appropriate physical exercise model to induce such adaptations ${ }^{9,10}$, which can have a positive effect in terms of reducing the number of falls and fractures, the prevention of the development of chronic-degenerative diseases, improved autonomy and functional independence, factors that contribute greatly to improving the quality of life of the elderly population ${ }^{11}$.
However, the effectiveness of the adoption of RT for the control of BP is still controversial, since the responses produced appear to be largely protocoldependent ${ }^{12,13}$. Thus, the choice of the exercises and the training system and the appropriate manipulation of the variables that compose RT programs, such as the order of execution, the number of series and repetitions, the load used, the speed of execution, the intervals between series and exercises and weekly frequency are fundamental aspects in terms of reaching the desired benefits ${ }^{14,15}$.

Therefore, despite the American College of Sports Medicine $(\mathrm{ACSM})^{16}$ recommending the regular practice of RT for the prevention and control of $\mathrm{AH}$, and the evidence produced so far on the possible positive impact of adopting this behavior having been confirmed in important systematic reviews with meta-analyzes ${ }^{17-21}$, the results provided in literature regarding this theme deserve to be analyzed in a more consistent manner, considering the diversity of systems of RT available in literature (traditional, pyramidal, circuit, super-set, pre-exhaustion, drop set, etc.) and the characteristics of the training protocols used (volume vs. intensity).

It is worth mentioning that $\mathrm{RT}$ systems allow the manipulation of the volume and intensity of training in different ways, providing different degrees of mechanical and metabolic stimuli. The traditional RT system is most often used in medium- and long-term studies aimed at investigating changes in the manifestation of force. This system has as its principle the use of fixed loads in each exercise, with the number of sets and repetitions being defined according to the objectives established for the training (strength, muscular endurance, hypertrophy, power, weight loss, among others) ${ }^{22}$.

Considering the popularity of the traditional RT system and its effectiveness in terms of improvement, especially of muscle strength and mass, fundamental variables for healthy aging, it is important to investigate the effectiveness or otherwise of this training system for the improvement of BP in the elderly. The objective of the study was therefore to analyze the effect of the regular practice of traditional RT for the control or reduction of BP in normotensive elderly individuals. 


\section{METHOD}

A systematic review of randomized clinical trials with meta-analyzes was performed according to the recommendations of the Cochrane Collaboration Hypertension Group ${ }^{23}$ and the PRISMA Statement ${ }^{24}$. The search strategy of the studies was elaborated by the authors of this study, without restriction by language. The databases investigated were: CENTRAL (The Cochrane Central Register of Controlled Trials Database); MEDLINE (Medlars Online); EMBASE (Excerpta Medica Database); LILACS (Latin American and Caribbean Health Sciences Literature); SCIELO (Scientific Electronic Library Online), Web of Science, Scopus and DARE (Database of Abstracts of Reviews of Effects). The descriptors used were: weight training, resistance training, strength training, blood pressure, hypertension, resistive exercise, randomized controlled trial, systematic review, elderly, older adults and meta-analysis. Manual searches were also performed based on the analysis of the bibliographic references of previously selected articles.

Randomized clinical trials on the effects of traditional RT on resting BP or on the treatment and/or maintenance of high BP published from January 1966 to June 2016 were selected for this investigation. The inclusion criteria of the studies selected for analyzes were: (1) samples composed of clinically healthy elderly individuals who did not report using hypertensive medication, and who were sedentary or moderately active; (2) the presence of a control group; (3) comparative data between the groups reported; (4) a minimum of four weeks of intervention; (5) adoption of the traditional RT system, regardless of the number of exercises. The period of the study search and data collection by the authors of this study was from January to July 2016.

To evaluate the quality of the studies included in this investigation, a risk of bias analysis was undertaken. The criteria of the Cochrane Back Review Group ${ }^{25}$ were used in the evaluations, in accordance with the experimental design used. The scale indicated for analysis is composed of 12 questions that must be answered with yes, no or not clear (Table 1). To be considered to have a low risk of bias the study must reach a minimum score of six points ${ }^{25}$. The risk of bias for each of the studies was assessed by two independent authors, each of whom assigned a score according to the established criteria. When there was disagreement between the two, a third reviewer with experience in this type of analysis was invited to decide upon the evaluation.

Chart 1. Evaluation of risk of bias. Paraná, 2016.

\begin{tabular}{|c|}
\hline Questions for evaluation of risk of bias \\
\hline Was an adequate randomization method employed? \\
Was the allocation of randomization adequate? \\
Was there masking of the patients? \\
Was there masking of the trainers? \\
Was there masking of the evaluators? \\
Were losses acceptable and were they described? \\
Were the participants assessed in the group to which they were allocated? \\
Were the results described free of outcome selection? \\
Were the groups similar at baseline? \\
Were other interventions avoided or similar? \\
Was adherence acceptable in all the groups?
\end{tabular}


The analyzes were grouped according to the duration of the training (up to 12 weeks and over 12 weeks). For continuous variables, the mean difference (MD) was used, with a 95\% confidence interval and a random effect model. To examine the sensitivity effect of each study on the overall results, analyzes were also performed with the one-to-one studies of the model removed. In order to evaluate the percentage of agreement of the risk of bias results of the studies analyzed between the two evaluators, the Kappa coefficient was used.

\section{RESULTS}

Initially, 562 articles were found and had their abstracts consulted. Of these, 533 studies were excluded as they were not related to the subject (other types of training or population) or were not randomized clinical trials. Of the 29 remaining studies, 23 were excluded because they presented inadequate or non-existent information on randomization or because they presented outcomes that did not meet the specific objectives of this study (Figure 1). Thus, six studies were included in this review ${ }^{26-31}$.

The main information from the included studies regarding the analysis of the effects of traditional RT on BP in the elderly is presented in chart 2. The total number of participants investigated was 187 elderly persons. The sample size in each study ranged from 17 to 40 participants. In three studies the participants were of both genders ${ }^{26,27,29}$ while the others used only female subjects ${ }^{28,30,31}$. The duration of the intervention ranged from eight to 24 weeks, with a frequency of three sessions per week. All studies used the auscultatory method to assess resting BP.

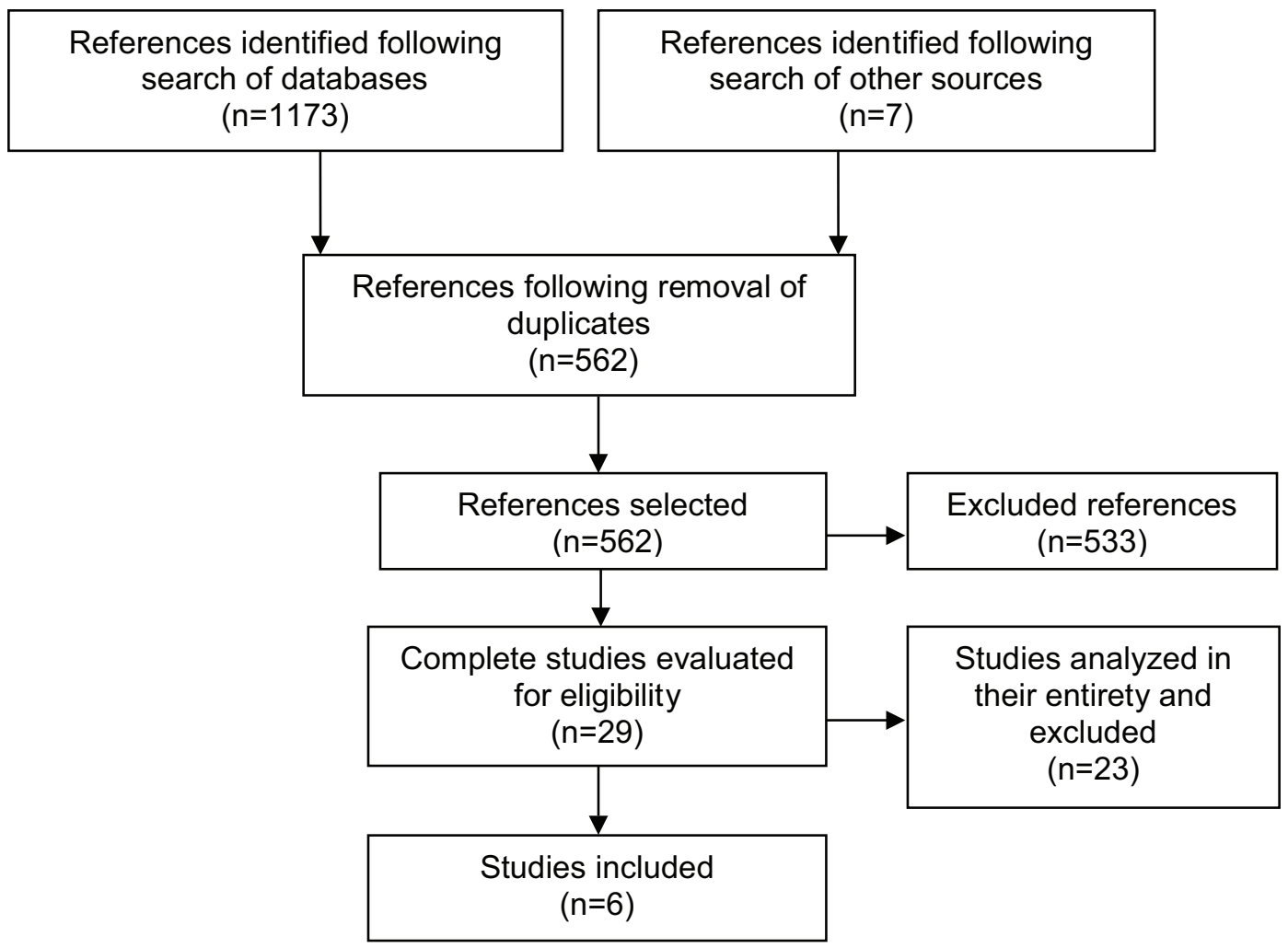

Figure 1. Algorithm of study selection. Paraná, 2016. 
Chart 2. Characteristics of studies selected for assessment of impact of traditional resistance training on blood pressure of elderly persons. Paraná, 2016.

\begin{tabular}{|c|c|c|c|}
\hline Studies & Participants & Characteristics and training time & $\begin{array}{l}\text { Protocol of BP } \\
\text { evaluation }\end{array}$ \\
\hline $\begin{array}{l}\text { Cononie et al. } \\
(1991)^{26}\end{array}$ & $\begin{array}{l}\text { N=21 Men/Women } \\
\text { ( } 70 \text { to } 79 \text { years) } \\
\text { RTG }=14 \\
\text { CG }=7\end{array}$ & $\begin{array}{l}\text { RTG }=\text { Traditional (Nautilus), } \\
72-79 \% \text { 1RM, } \\
1 \text { series, 8-12 rep, } \\
\text { 60'-120' rep, } 10 \text { ex. } \\
24 \text { weeks, } 3 \text { x por week. }\end{array}$ & $\begin{array}{l}\text { Auscultatory } \\
\text { (9 measures), } \\
\text { Seated Rst } \\
\text { (15 min). Morning. }\end{array}$ \\
\hline $\begin{array}{l}\text { Tsutsumi et al. } \\
(1997)^{27}\end{array}$ & $\begin{array}{l}\mathrm{N}=19 \text { Men, Women } \\
(61 \text { to } 86 \text { years }) \\
\mathrm{RTG}_{\text {high int }}=14(67.8 \pm 4.9) \\
\mathrm{RTG}_{\text {low int }}=13(68.9 \pm 7.5) \\
\mathrm{CG}=14(69.8 \pm 4.6)\end{array}$ & $\begin{array}{l}\text { RTG }=\text { Traditional } \\
\text { (Weight Machine) } \\
2 \text { series, } 12 \text { ex, } 60-120 \text { 'rep. } \\
\text { RTG }{ }_{\text {high int }}=75-85 \% 1 \mathrm{RM}, \\
12-16 \text { rep. } \\
\text { RTG }{ }_{\text {low int }}=55-65 \% \text { of } 1 \mathrm{RM}, 8-12 \text { rep. } \\
12 \text { weeks, } 3 \text { x por week }\end{array}$ & $\begin{array}{l}\text { Auscultatory } \\
\text { Seated Rst }\end{array}$ \\
\hline $\begin{array}{l}\text { Wood et al. } \\
(2001)^{28}\end{array}$ & $\begin{array}{l}\mathrm{N}=17 \text { Women } \\
(60 \text { to } 84 \text { years }) \\
\mathrm{RTG}=11(69.8 \pm 6) \\
\mathrm{CG}=6(68 \pm 5.4)\end{array}$ & $\begin{array}{l}\text { RTG }=\text { Traditional } \\
75 \% \text { 5RM, } 2 \text { series, } \\
\text { 8-12 rep., 8ex. } \\
12 \text { weeks, 3x por week. }\end{array}$ & $\begin{array}{l}\text { Auscultatory } \\
\text { Seated Rst }\end{array}$ \\
\hline $\begin{array}{l}\text { Vicent et al. } \\
(2003)^{29}\end{array}$ & $\begin{array}{l}\mathrm{N}=62 \text { Men, Women } \\
(60 \text { to } 85 \text { years) } \\
\mathrm{RTG}_{\text {high int }}=24(66.6 \pm 7) \\
\mathrm{RTG}_{\text {low int }}=22(67.6 \pm 6) \\
\mathrm{CG}=16(71 \pm 5)\end{array}$ & $\begin{array}{l}\text { RTG }=\text { Traditional } \\
1 \text { series, } 13 \text { ex. } \\
\text { RTG }_{\text {high int }}=8 \text { rep, } 80 \% 1 \mathrm{RM} \\
\text { RTG }_{\text {low int }}=13 \text { rep, } \\
50 \% 1 \mathrm{RM} \\
24 \text { weeks, } 3 x \text { por week. }\end{array}$ & $\begin{array}{l}\text { Auscultatory } \\
\text { (6 measures) } \\
\text { Seated Rst } \\
(15 \mathrm{~min})\end{array}$ \\
\hline $\begin{array}{l}\text { Gerage et. al } \\
(2013)^{30}\end{array}$ & $\begin{array}{l}\mathrm{N}=29 \text { Women, } \\
\text { (over } 60 \text { years) } \\
\text { RTG }=15(65.5 \pm 5) \\
\text { CG }=14(66.2 \pm 4,1)\end{array}$ & $\begin{array}{l}\text { RTG }=\text { Traditional } \\
2 \text { series, } 8 \text { ex. } \\
10-15 \text { rep. } \\
12 \text { weeks, } 3 x \text { por week. }\end{array}$ & $\begin{array}{l}\text { Auscultatory } \\
\text { (Mean of } 9 \\
\text { measures) } \\
\text { Seated Rst }\end{array}$ \\
\hline $\begin{array}{l}\text { Gurjão et. Al } \\
(2013)^{31}\end{array}$ & $\begin{array}{l}\mathrm{N}=17 \text { Women, } \\
(66 \pm 5.8 \text { years }) \\
\mathrm{RTG}=10 \\
\mathrm{CG}=7\end{array}$ & $\begin{array}{l}\text { RTG }=\text { Traditional } \\
3 \text { series, } 7 \text { ex. } \\
10-12 \text { rep. } \\
8 \text { weeks, } 3 x \text { por week. }\end{array}$ & $\begin{array}{l}\text { Auscultatory } \\
\text { Seated Rst }\end{array}$ \\
\hline
\end{tabular}

Ex = Exercises; CG = Control Group; RTG = Resistance Training Group; N = Number of participants; Rep = repetitions; Rst = resting; Week. $=$ weeks; int $=$ intensity.

In the evaluation of risk of bias of the Furlan et al. ${ }^{25}$ score table (Table 1), only the studies by Cononie et al. ${ }^{26}$ and Wood et al. ${ }^{28}$ were considered to have a high risk of bias as they scored only five points in the evaluation criteria. One study achieved the minimum required score (six points for low risk of bias) ${ }^{27}$, while the other studies scored seven points. However, only the study by Vicent et al. ${ }^{29}$ met the rules of the Cochrane Collaboration for the randomization of participants. No study concealed the allocation of included subjects and/or masked the evaluators. The agreement between the reviewers on the assessment of the risk of study bias was considered high (Kappa $=0.81)$.
The analysis of the SBP and DBP outcomes of the six selected studies is shown in Tables 1 and 2, respectively. Four studies presented a training time of

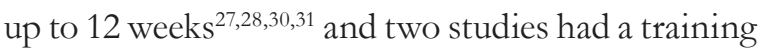
time greater than 12 weeks $^{26,29}$. Two studies were separated according to the intensity used (low and high intensity) ${ }^{27,29}$, although this strategy generated a doubling of the total number of Control Group participants ( $\mathrm{n}=94)$ in these studies (Tables 1 and 2). Considering that the studies were divided into two subgroups by duration, the total real participation was 123 individuals in the training group and 64 in the control group. 


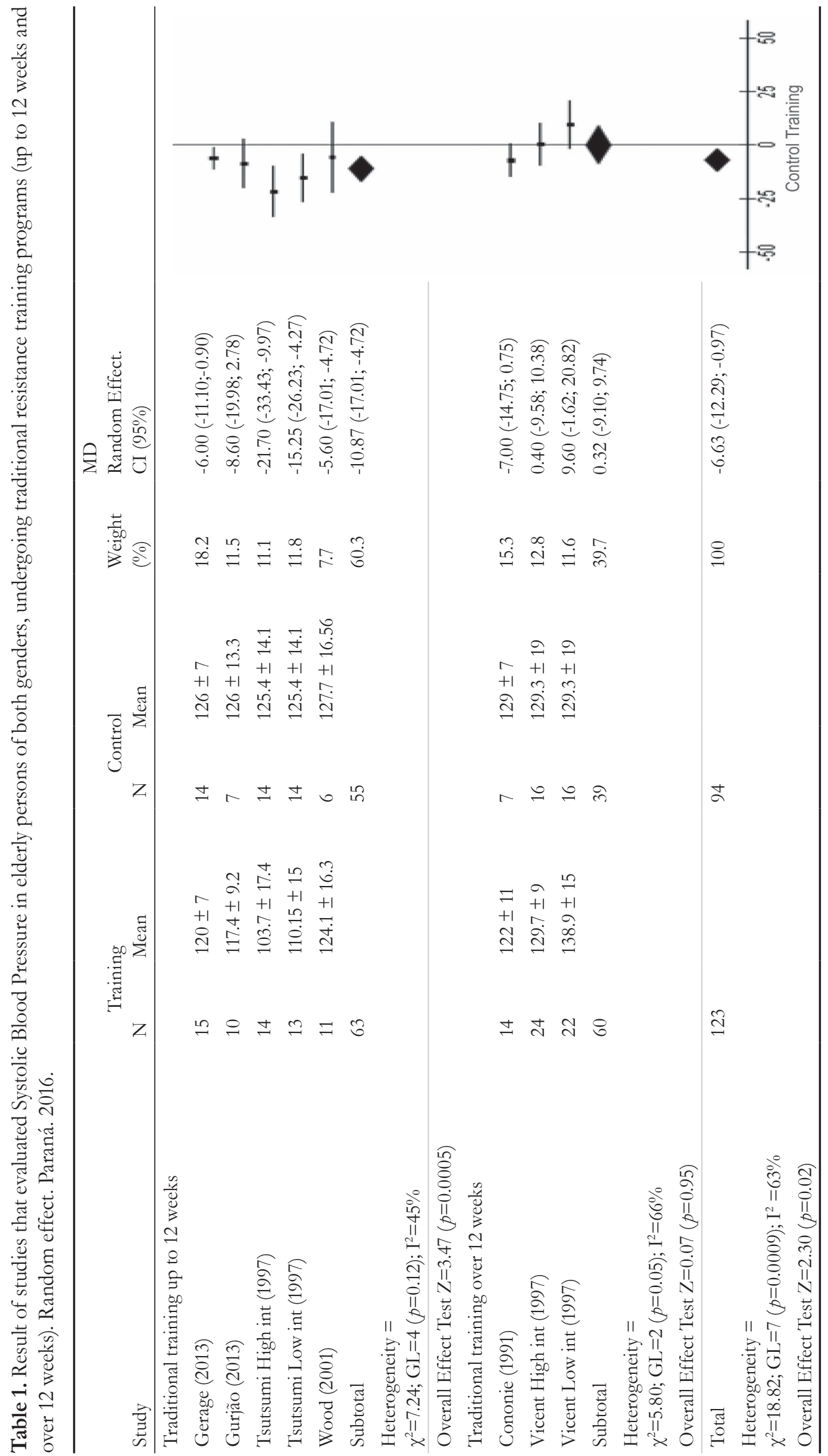




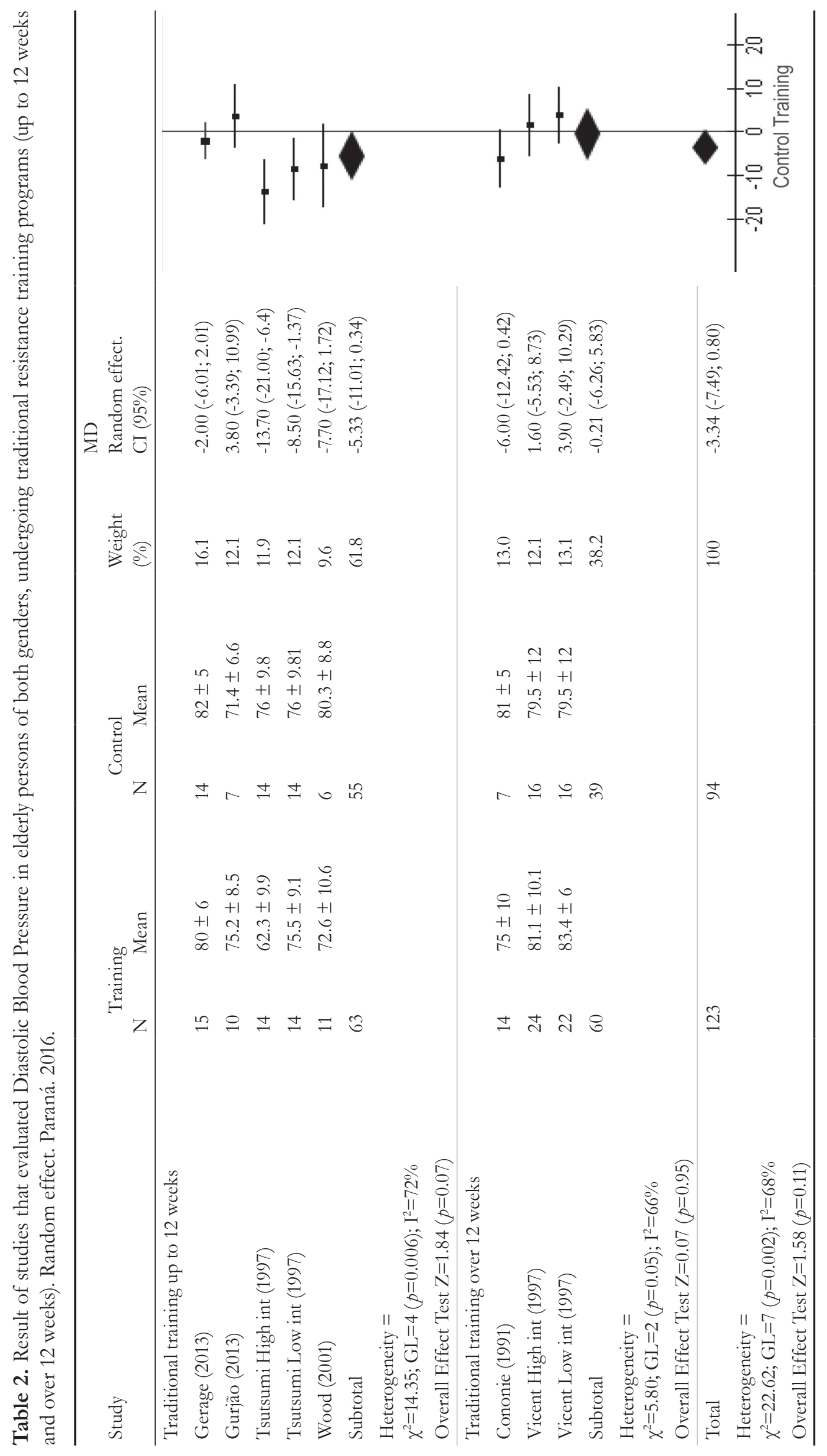


A statistically significant reduction $(p=0.02)$ in SBP of $-6.63 \mathrm{mmHg}(95 \% \mathrm{CI}=-12.29 ;-0.97)$ was associated with the practice of RT (Table 1), with the greatest reductions being identified in studies that employed an intervention time of up to 12 weeks (-10.87 mmHg; CI: -17.01; -4.72). For DBP, the metaanalysis presented a reduction of $-3.34 \mathrm{mmHg}(95 \%$ CI $=-7.49 ; 0.80)(p=0.11)$ (Table 2$)$.

\section{DISCUSSION}

The main finding of the present study is that the traditional RT system can significantly reduce SBP in the elderly even over relatively short intervention periods ( $<12$ weeks). This is the first study that analyzed the impact of RT on BP behavior in the elderly population, based on a specific RT system. The information produced is relevant, since the effectiveness of the traditional RT system in terms of the possible hemodynamic adaptations produced over time has not yet been carefully analyzed in literature, despite being one of the most used systems by practitioners of resistance exercises in different age groups, with proven efficacy for the improvement of several components of physical fitness.

It is worth noting that the traditional RT system is considered one of the most well-known internationally, being much used by beginners, the elderly or those who are returning to practice after a period of absence ${ }^{22}$. In addition, the traditional RT system allows training of the entire body in a single training session, in which exercises are performed in sequence, in single or multiple series, with fixed loads. In addition, the order of execution of the exercises can be structured by means of a system that alternates by segment or located by joint, according to the time available for the training or the level of physical conditioning of the practitioner.

The regular practice of $\mathrm{RT}$ has been widely recommended, especially for the elderly population, as it is easy to apply and allows the individual structuring of exercise programs according to the needs and objectives of each practitioner ${ }^{5}$. It can also be safely performed, due to the absence of rapid movements and decelerations, presenting a low risk for the development of lesions ${ }^{32}$. RT has also been adopted for the prevention or control of cardiovascular diseases, such as $\mathrm{AH}^{33}$. In this context, the reductions in $\mathrm{BP}$ in the elderly persons identified in this study, when analyzed in total numbers, are greater than those found in studies that described the same outcomes in normotensive $e^{34-37}$ and hypertensive adults ${ }^{38}$.

A number of recent randomized trials that investigated the effect of resistance exercise on BP in the elderly adopted the isometric training model using handgrip dynamometry, with results varying from no change ${ }^{39}$ to reductions between $-5 \mathrm{mmHg}^{40}$ and $-19 \mathrm{mmHg}^{41}$. Despite some researchers ${ }^{19,21,42}$ defending this model of exercise for the reduction of $\mathrm{BP}$ in different populations, such a model presents restricted and somewhat limited application ${ }^{43}$, since in contrast to RT, it does not result in additional adaptations for the different body segments, such as gains in muscle mass, resistance and muscle power, increased density and bone mineral content, among other benefits considered fundamental for the health of the elderly.

Regarding the duration of the RT protocols, the results of the meta-analyzes identified greater reductions in $\mathrm{BP}$ in protocols of up to 12 weeks. It is believed that differences in the magnitude of chronic hypotensive responses related to the time of the RT may also be related to the training adjustments influenced by the condition of the individual, as well as to the manipulation of the variables that compose the RT programs and which guarantee the volume and the intensity necessary to induce adaptive responses.

Four of the studies analyzed involved an intervention for 12 weeks s, $28,30,31$, with a longer intervention in only two studies ${ }^{26,28}$. The works of Tsutsumi et al. ${ }^{27}$ and Vicent et al. ${ }^{29}$, which obtained contradictory results despite featuring high and low intensity groups of equal design, are worthy of note. Therefore, it seems that the manipulation of the training characteristics of the studies of this metaanalysis alone was not sufficient to explain the greater reductions found in studies with a lower training time. One possible explanation could be the training pattern found in untrained individuals, where greater alterations, both neuromotor and cardiovascular, occur in the first weeks of intervention ${ }^{14}$.

Regarding the possible mechanisms involved in the alteration of BP through RT, randomized clinical trials in different populations attributed this 
reduction to mechanisms such as the reduction of cardiac output and peripheral vascular resistance ${ }^{36}$, alterations in sympathetic nervous activity and vasodilatory substances ${ }^{33,36}$, and the sensitization of baroreceptor and parasympathetic mechanisms $\mathrm{s}^{4,45}$. However, in the elderly population, alterations in BP may involve all or a large number of these factors ${ }^{21}$. In our review, Tsutsumi et al. ${ }^{27}$ reported a reduction of SBP and DBP, while the study conducted by Gerage et al. ${ }^{30}$ found a reduction only in SBP. However, the authors did not attribute their findings to a mechanism of BP control, but instead inferred that $\mathrm{RT}$ is associated with the physiological benefits that come with the reduction of BP. It is important to note that most of the studies reviewed did not evaluate the possible mechanisms of BP control.

Cononie et al. ${ }^{26}$ reported a non-significant reduction in $\mathrm{BP}$ values with $\mathrm{RT}$, when investigating possible mechanisms of BP control. However, there were no changes in the plasma norepinephrine and epinephrine and angiotensin I and II mechanisms in the control and training groups, which may suggest the possible adaptation or failure of BP control mechanisms in the elderly population who did or did not exercise.

One aspect that deserves to be highlighted in this review is that all the studies included underwent quality assessments. However, the small number of investigations that met the established criteria indicates the need for new, well-controlled research that confirms or refutes the results found so far in the elderly population. On the other hand, the main limitations of this study are directly related to the information found in the clinical trials evaluated, principally the small number of studies and the size of the samples. Another limitation was the impossibility of verifying the effect of RT on hypertensive elderly persons, as literature presents only three randomized clinical trials for this population ${ }^{26,38,39}$, all of which have different types of training, which makes it difficult to compare the findings.

The need for new studies to investigate the effectiveness of $\mathrm{RT}$ on resting $\mathrm{BP}$, using different training systems, in normotensive and hypertensive elderly individuals, is therefore evident. It is suggested that randomized clinical trials are conducted in accordance with the CONSORT guidelines ${ }^{46}$, have responses free of bias, and contribute to professional decision-making.

Despite the limitations described in terms of the biases found in this review, the results presented are especially important for clinical and/or professional practice since the reductions in BP highlighted in the present investigation indicate a possible nonpharmacological alternative to the treatment or maintenance of elevated BP in the elderly. Literature has shown that a reduction of $2 \mathrm{mmHg}$ in $\mathrm{BP}$ can reduce the risk of death due to strokes by up to $6 \%$ and those due to coronary diseases by up to $4 \%$, while a reduction of $5 \mathrm{mmHg}$ in $\mathrm{BP}$ can represent a $14 \%$ reduction in the risk of death from strokes and $9 \%$ from coronary diseases ${ }^{47}$.

\section{CONCLUSIONS}

The present study provides information about the effectiveness of traditional system RT to reduce resting SBP values for normotensive elderly individuals in comparison with the non-performance of systematized exercises.

This information may assist professionals in clinical practice with the development of nonpharmacological strategies targeted at the prevention and control of BP in elderly individuals.

\section{REFERENCES}

1. Mahmood SS, Levy D, Vasan RS, Wang TJ. The Framingham Heart Study and the epidemiology of cardiovascular disease: a historical perspective. Lancet 2014;383(9921):999-1008.
2. James PA, Oparil S, Carter BL, Cushman WC, Dennison-Himmelfarb C, Handler, J, et al. 2014 Evidence-based guideline for the management of high blood pressure in adults: report from the panel members appointed to the Eighth Joint National Committee (JNC 8). Jama 2014;311(5):507-520. 
3. Rapsomaniki, E, Timmis A, George J, PujadesRodriguez M, Shah AD, Denaxas, S, et al. Blood pressure and incidence of twelve cardiovascular diseases: lifetime risks, healthy life-years lost, and agespecific associations in 1. 25 million people. Lancet 2014;383(9932):1899-1911.

4. Brasil. Ministério da Saúde. Secretaria de Vigilância em Saúde. Vigitel Brasil 2013: vigilância de fatores de risco e proteção para doenças crônicas por inquérito telefônico / Ministério da Saúde, Secretaria de Vigilância em Saúde. - Brasília: Ministério da Saúde, 2014.

5. Nelson ME, Rejeski WJ, Blair SN, Duncan PW, Judge JO, King AC, Macera CA, Castanedasceppa C. Physical activity and public health in older adults: Recommendation from the American College of Sports Medicine and the American Heart Association. Med Sci Sports Exerc 2007;39(9):1435-1445.

6. Ash GI, Macdonald HV, Pescatello LS. Antihypertensive effects of exercise among those with resistant hypertension. Hypertension 2013; 61(1):e1.

7. Molmen-Hansen HE, Stolen T, Tjonna AE, Inger LA, Inga SE, Gjertrud AT, et al. Aerobic interval training reduces blood pressure and improves myocardial function in hypertensive patients. Eur J Prev Cardiol 2012;19(2):151-60.

8. Huang G, Shi X, Gibson CA, Huang SC, Coudret NA, Ehlman MC. Controlled aerobic exercise training reduces resting blood pressure in sedentary older adults. Blood Press 2013;22(6):386-394.

9. Câmara LC, Santarém Sobrinho JM, J Filho W. Exercícios resistidos em idosos portadores de insuficiência arterial periférica. Acta Fisiátrica 2006;13(2):96-102.

10. Santarém Sobrinho JM. Princípios profiláticos e terapêuticos do exercício. In: Amatuzzi MM, Greve JMD, Carazazato JG. Reabilitação em medicina do esporte. 1a. ed. São Paulo: Roca Ltda 2004;17-25.

11. Queiroz ACC, Kanegusuku H, Forjaz CLM. Efeitos do treinamento resistido sobre a pressão arterial de idoso. Arq Bras Cardiol 2010;95(1):135-140.

12. Souza NS, Gomides RS, Silva GV, Moraes FCL, Mion $\mathrm{D} J r$, Tinucci T. Intra-arterial blood pressure response in hypertensive subjects during low- and highintensity resistance exercise. Clinics 2010;65(3):271-7.

13. Jannig PR, Cardoso AC, Fleischmann E, Coelho CW, Carvalho T. Influencia da ordem de execução de exercícios resistidos na hipotensão pós-exercício em idosos hipertensos. Rev Bras Med Esporte 2009;15(5):338-41.

14. Westcott WL. Resistance training is medicine: effects of strength training on health. Curr Sports Med Rep 2012;11(4):209-16.
15. Prestes J, Nascimento DC, Tibana RA, Teixeira TG, Vieira DCL, Tajra V, Farias DL, Silva AO, Funghetto SS, Souza VC, Navalta JW. Understanding the individual responsiveness to resistance training periodization. Age 2015;37(3):1-13.

16. American College of Sports Medicine. ACSM stand position on exercise and hypertension. Med Sci Sports Exerc 2004;36:533-53.

17. Cornelissen VA, Fagard RH, Coeckelberghs E, Vanhees L. Impact of resistance training on blood pressure and other cardiovascular risk factors: A meta-analysis of randomized, controlled trials. Hypertension 2011;58(5):950-958.

18. Cornelissen, Veronique A. and Neil A. Smart. Exercise training for blood pressure: a systematic review and meta-analysis. J Am Heart Assoc 2013;2(1):1-9.

19. George A. Kelley and Kristi S. Kelley. Isometric handgrip exercise and resting blood pressure: a metaanalysis of randomized controlled trials. J Hypertens 2010;28(3):411-418.

20. Owen A, Wiles J, Swaine I. Effect of isometric exercise on resting blood pressure: a meta analysis. J Hum Hypertens 2010;24(12):796-800.

21. Carlson DJ, Dieberg G, Hess NC, Millar PJ, Smart NA. Isometric exercise training for blood pressure management: A systematic review and meta-analysis. Mayo Clin Proc 2014;89(3):327-334.

22. Uchida MC, Charro MA, Bacurau RFP, Navarro F, Pontes FL. Manual de musculação: Uma abordagem teórico-prática do treinamento de força. $7^{\mathrm{a}}$ edição. São Paulo. Phorte. 2015.

23. Higgins JPT, Green S. Cochrane handbook for systematic reviews of interventions version 5.1.0 [updated March 2011]. The Cochrane Collaboration, 2011.

24. PRISMA Improving quality of reports of metaanalyses of randomized controlled trials: The QUOROM statement. Lancet 1999;354:1896-1900.

25. Furlan AD, Victoria PRN, Claire BMD, Maurits VT. 2009 Updated method guidelines for systematic reviews in the Cochrane Back Review Group. Spine 2009;34(18):1929-1941.

26. Cononie CC, Graves JE, Pollock ML, Phillips MI, Sumners C, Hagberg JM. Effect of exercise training on blood pressure in 70- to 79-yr-old men and women. Med Sci Sports Exerc 1991;23(4):505-11.

27. Tsutsumi T, Don BM, Zaichkowsky LD, Delizonna LL. Physical fitness and psychological benefits of strength training in community dwelling older adults. Appl Human Sci 1997;16(6):257-66. 
28. Wood RH, Reyes R, Welsch MA, Favaloro-Sabatier J, Sabatier M, Lee CM, Johnson LG, Hooper PF. Concurrent cardiovascular and resistance training in healthy older adults. Med Sci Sports Exerc 2001;33(10):1751-1758.

29. Vincent KR, Vincent HK, Braith RW, Bhatnagar V, Lowenthal DT. Strength training and hemodynamic responses to exercise. Am J Geriatr Cardiol 2003;12(2):97-106.

30. Gerage AM, Forjaz CLM, Nascimento MA, Januário RSB, Polito MD, Cyrino ES. Cardiovascular adaptations to resistance training in elderly postmenopausal women. Int J Sports Med 2013;34(9):806-813.

31. Gurjao ALD, Goncalves R, Carneiro NH., Ceccato M, Jambassi Filho JC, Gobbi S. Efeito do treinamento com pesos na pressão arterial de repouso em idosas normotensas. Rev Bras Med Esporte 2013;19(3):160-163.

32. Krist L, Dimeo F, Keil T. Can progressive resistance training twice a week improve mobility, muscle strength, and quality of life in very elderly nursinghome residents with impaired mobility? A pilot study. Clin Interv Aging 2013;8:443-448.

33. Tomeleri CM, Marcori AJ, Ribeiro AS, Gerage AM, de Souza Padilha C, Schiavoni D, et al. Chronic blood pressure reductions and increments in plasma nitric oxide bioavailability. Int J Sports Med, 2017;38(4):290-299.

34. Sarsan A, Ardic F, Ozgen M, Topuz O, Sermez Y. The effects of aerobic and resistance exercises in obese women. Clin Rehab 2006;20(9):773-82.

35. Sallinen J, Fogelholm M, Volek JS, Kraemer WJ, Alen M, Häkkinen K. Effects of strength training and reduced training on functional performance and metabolic health indicators in middle-aged men. Int J Sports Med 2007;28(10):815-82.

36. Gerage AM, Cyrino ES, Schiavoni D, Nakamura FY, Ronque ERV, Gurjão ALD, Gobbi S. Efeito de 16 semanas de treinamento com pesos sobre a pressão arterial em mulheres normotensas e não-treinadas. Rev Bras Med Esporte 2007;13:361-65.

37. Yoshizawa M, Maeda S, Miyaki A, Misono M, Saito Y, Tanabe K, Kuno S, Ajisaka R. Effect of 12 weeks of moderate-intensity resistance training on arterial stiffness: A randomized controlled trial in women aged 32-59. Rev Bras Med Esporte 2009;43(8):615-8.
38. Gonçalves CG, Nakamura FY, Polito MD, Gerage AM, Januario RS, Nascimento MA, Farinatti PT. Functional and physiological effects of a 12 -week programme of resistance training in elderly hypertensive women: original research article. Int Sport Med J 2014;15(1):50-61.

39. Stiller-Moldovan C, Kenno K, McGowan CL. Effects of isometric handgrip training on blood pressure (resting and $24 \mathrm{~h}$ ambulatory) and heart rate variability in medicated hypertensive patients. Blood Press Monit 2012;17(2):55-61.

40. Badrov MB, Bartol CL, Di Bartolomeo MA, Millar PJ, McNevin NH, McGowan CL. Effects of isometric handgrip training dose on resting blood pressure and resistance vessel endothelial function in normotensive women. Eur J Appl Physiol 2013;113(8):2091-2100.

41. Taylor AC, McCartney N, Kamath MV, Wiley RL. Isometric training lowers resting blood pressure and modulates autonomic control. Med Sci Sports Exerc 2003;35(2):251-6,2003.

42. Millar PJ, McGowan CL, Cornelissen VA, Araujo CG, Swaine IL. Evidence for the role of isometric exercise training in reducing blood pressure: potential mechanisms and future directions. Sports Med 2014 Mar;44(3):345-56.

43. Fleck SJ e Kraemer WJ. Fundamentos do treinamento de força. $4^{\mathrm{a}}$ ed. Porto Alegre: Artmed; 2017.

44. Devereux GR, Wiles JD, Howden R. Immediate postisometric exercise cardiovascular responses are associated with training-induced resting systolic blood pressure reductions. Eur J Appl Physiol 2015;115(2):327-333.

45. Vincent KR, Vincent HK, Braith RW, Bhatnagar V, Lowenthal DT. Strength training and hemodynamic responses to exercise. Am J Geriatr Cardiol 2003;12(2):97-106.

46. Schulz K F, Altman DG, Moher D. CONSORT 2010 Statement: Updated guidelines for reporting parallel group randomized trials. Ann of Intern Med 2010;152(11):726-732.

47. Cornelissen VA, Buys R, Smart NA. Endurance exercise beneficially affects ambulatory blood pressure: a systematic review and meta-analysis. J Hypertens 2013;31:639-48. 